\title{
Subsidies for Private Community Services: The Case of School Education
}

\author{
Buly Cardak and Phillip Hone
}

\begin{abstract}
$\mathrm{P}$ ublic policy makers in Australia face an economic and political environment with actual and potential conflicts that make policy formulation difficult. For example, there is a strong commitment on both sides of Parliament to surplus, or at least, balanced budgets. At the same time policy makers in the major parties appear to believe that the median voters in the marginal electorates are opposed to higher income taxes. These factors are coupled with wider community concern about the level of provision of government services in key areas such as education, hospitals and transport. As a consequence governments are in a policy dilemma: they are constantly under pressure to improve the provision of public services, while there are also strong expectations that they will manage the macro economy in such a way as to show budgetary restraint without raising taxes. In effect, they are being asked to provide more services without raising more revenue.

The only avenue open to governments to achieve these potentially competing goals is to be more efficient in the use of the existing government revenue base. One of the more controversial policy initiatives to deal with these competing demands has been the use of government subsidies to encourage the growth of private sector provision of community services. In this regard the Federal Government encourages people to use the private rather than public hospital systems by subsidising private health insurance. Similarly, significant Commonwealth funding is made available to non-government schools. These policies are designed, at least in part, to use some public funds to leverage greater private contributions into the provision of community services.

Both health and education subsidies have been the subject of considerable debate. While there is a number of issues and principles that are disputed in these debates, a key issue relates to how to ensure adequate funding for the public sector. Opponents argue that governments should ensure that scarce public funds are directed towards the public systems and not diverted to encourage growth of a competing system. Supporters have contended that in a political environment where higher taxes are not perceived as being feasible, the growth of the private sector is necessary to ensure that the demand on the public sector does not outstrip the supply of public sector resources.
\end{abstract}

Buly Cardak is a lecturer in Economics in the Department of Economics and Finance, La Trobe University, and Phillip Hone is a Senior Lecturer in Economics at the School of Economics, Deakin University. 
In this paper we examine the economics of public funding of private sector provision of community services by examining the case of Commonwealth funding of the non-government school system.

Public schools are funded principally by state governments, while government funding of non-government schools is primarily a Commonwealth initiative. Non-government schools have received Commonwealth subsidies in one form or another since 1964 with formal recurrent grants commencing in 1970. Although the magnitude of the funding involved is not substantial in a national budgetary sense, the level of funding is growing and, most importantly, it has always been significant in a wider public policy context.

\section{Table 1: Government Expenditure on Government and Non- Government Schools, 1977 and 1999-2000}

\begin{tabular}{|c|c|c|c|c|}
\hline & \multicolumn{2}{|c|}{ Government Schools } & \multicolumn{2}{|c|}{$\begin{array}{l}\text { Non-Government } \\
\text { Schools }\end{array}$} \\
\hline & $1977^{\mathrm{a}}$ & $1999-2000$ & $1977^{\mathrm{a}}$ & 1999-2000 \\
\hline $\begin{array}{l}\text { Commonwealth } \\
\text { Expenditure }(\$ \mathrm{~m})\end{array}$ & -- & 1786 & -- & 2900 \\
\hline State Expenditure $(\$ \mathrm{~m})$ & -- & 14806 & -- & 1195 \\
\hline $\begin{array}{l}\text { Total Public } \\
\text { Expenditure }(\$ \mathrm{~m})\end{array}$ & $9656^{\mathrm{b}}$ & 16592 & $1051^{b}$ & 4096 \\
\hline $\begin{array}{l}\text { Enrolments } \\
\text { (Primary + Secondary) }\end{array}$ & 2364300 & $2259829^{\mathrm{c}}$ & 630900 & $999565^{\mathrm{c}}$ \\
\hline $\begin{array}{l}\text { Total Spending per } \\
\text { student }(\$)\end{array}$ & 4084 & 7344 & 1666 & 4139 \\
\hline
\end{tabular}

Notes: a: Values for 1977 have been indexed to 2000 dollar terms using the CPI.

b: Education expenditure data for 1977 is not available by source (Commonwealth or State Government) in the Commonwealth Schools Commission publication 'Australian Students and Their Schools'.

c: These enrolment figures are for 2000 rather than 1999-2000.

Sources: Steering Committee for the Review of Commonwealth/State Service Provision SCRCSSP (2002):Attachment 3A (Tables 3A.1, 3A.2 and 3A.11);

Ministerial Council on Education, Employment, Training and Youth Affairs (2003):Appendix 1 (Table 27);

Commonwealth Schools Commission and Australian Bureau of Statistics (1979). 
In 1977 a total of $\$ 1051$ million (adjusted to year 2000 dollars) of Commonwealth and State funds were allocated to non-government schools. This represented \$1,666 per student in non-government schools and was equivalent to 41 per cent of the average cost of educating a student at a government school. By the year 2000, total public funding to non-government schools had grown to just over $\$ 4,000$ million, with $\$ 2,900$ million provided by the Commonwealth. Total government funding was equivalent to $\$ 4139$ per student enrolled outside the government system or 59 per cent of the cost of educating a student in a government secondary school.

The aim of this paper is to explore some of the economic issues associated with this funding strategy. This analysis is essentially positive in perspective. We do not address normative issues such as the desirability of potentially transferring tax revenue to middle and high income voters. Moreover, while our analysis is consistent with the notion that the current regime of subsidies for private schooling could be a means of making increasingly scarce public funding available for the public school system or other government services, we are not arguing that budgetary efficiency is the only or even the most important objective that government is pursuing with this policy approach. Rather, we focus on the task of identifying the conditions under which the current regime of subsidies for private schooling could reduce the effective real demand on public resources because this is an important policy issue in its own right.

Given the controversy surrounding recent changes in the Commonwealth funding mechanism for non-government schools (see, for example, Maslen, 2000; Donnelly, 2001; and Sydney Morning Herald, 2002) we outline the previous and existing Commonwealth funding arrangements in the next section. We then move to identify the conditions that need to exist for public subsidies of private schools to potentially result in more public resources for students at government schools and consider if these conditions are likely to be met in the current Australian education sector. This is followed by an evaluation of the current subsidy program in terms of its effectiveness in providing choice and improving resources in both public and private schools. The final section highlights the policy implications and presents a summary of conclusions.

\section{Government Subsidies for Non-Government Schools}

The two most recent schemes of allocating Commonwealth funds to nongovernment schools are the Education Resources Index (ERI) funding scheme, which began in 1985 and applied until 2001 when the Socio-Economic Status (SES) funding scheme was partially introduced.

The ERI funding scheme was intended to measure a school's private income and compare it to 'The Community Standard', or later, 'The Average Government School Recurrent Costs', and to subsidise schools in a way that would bring them closer to the relevant standard, thereby providing students with similar funding resources independent of schooling system. The ERI defined school income broadly to include not only private fee income but also the estimated dollar value 
of volunteered services along with other non-cash donations, such as artwork. The scheme was based on a 12 category rating system, which was determined at the outset of the scheme, 1985. Ratings were not recalculated regularly and it was difficult to move to a lower ERI, which would entitle a school to greater funding. If the intention was to assist needy students attending private schools, the scheme seems to have been flawed in that it was based on school income rather than a student's family income. In any case, after a Commonwealth government review of schools funding, started in 1997, the funding system was changed in 2000. (Department of Employment, Education, Training and Youth Affairs, 1997 and 1998).

Currently, non-government schools outside the Catholic education system receive recurrent Commonwealth funding based on the SES of their respective school communities. All non-government schools had the option to continue on the ERI funding scheme and the Catholic school system - which comprises about 60 per cent of non-government school enrolments - elected to continue to be funded through the ERI framework. Non-government students comprise around 30 per cent of total enrolments, implying the SES funding scheme applies to 10 per cent of the student population. This decision is to be reviewed after four years, in 2005 .

A school's SES score is based on the places of residence of students and their families and draws on Australian Bureau of Statistics Census data. The SES index used by the Department of Education, Training and Youth Affairs (DETYA) comprises three dimensions: occupation, education and household income, with extra weight given to households with school age children (family income). Because of Census confidentiality requirements, students are attributed with average occupation, education and income values for the Census Collection District in which they reside. These values take the form of a standardised index. To calculate a school's SES index, the various attribute indices of each individual in the school community are averaged and then weighted into an aggregate SES index value for the school.

For example, the occupation indices for every student in the school are averaged to provide the schools average occupation index. This is also carried out for education levels and income. In order to place more weight on households with children, the income dimension is split into overall average income and average income of households with school age children. Once these average school dimension indices are calculated, they are aggregated using the following formula:

$$
\begin{aligned}
& \text { School SES Score }=\frac{\text { Occupation Dimension }}{3}+\frac{\text { Education Dimension }}{3} \\
& +\frac{\text { Household Income Dimension }}{6}+\frac{\text { Income of Families with Children Dimension }}{6}
\end{aligned}
$$

These school SES scores are then used to determine Commonwealth General Recurrent Grants per student for non-government schools outside the Catholic education system. Recurrent grants are based on Average Government School 
Recurrent Costs (AGSRC). The higher a school's SES score the lower is their Commonwealth General Recurrent Grant per student. For example, schools with a SES of 130 or greater will receive 13.7 per cent of AGSRC, the lowest level of funding. The Commonwealth General Recurrent Grant per student rises at a constant rate of 2.5 per cent for every two-point decrease in SES score. The highest Commonwealth General Recurrent Grant per student is 70 per cent of AGSRC for schools with a SES score of 85 or less. (For more details, see DETYA, 2000; and Commonwealth of Australia, 2001.)

\section{Efficacy of Subsidies for Non-Government Schooling}

A possible budgetary motivation underpinning government subsidies for private schooling is that by offering the individual a subsidy for private education, individuals may contribute to private education such that the sum of the public and the private contributions exceeds the sum that would be spent if education was provided completely from public resources. Whether this is the case or not depends critically on the nature of both the subsidy arrangements implemented and the competitive market relationships that exist in the educational sector. In this section we consider how market relationships influence the budgetary efficacy of current subsidy arrangements.

These competitive market relationships have both supply and demand elements. The key aspects of the demand relationships in the educational sector relate to how responsive parents are to changes in the cost of private education and to changes in the quality of public education. First, an underlying premise of the current funding arrangement is that reduced private school fees will shift substantial numbers of enrolments from the public sector to the private sector. This responsiveness to private school charges is the price elasticity of demand for private school education. If this elasticity is relatively low, subsidies will result in few students leaving the public sector to move to the private sector.

If a private education subsidy is less than what would be spent on the child in the public sector, a subsidy scheme may operate to increase per student expenditures on the students remaining in the public sector. This is based on the assumption that the cost savings are not used for some other public expenditure or to reduce taxes. Under the Enrolment Benchmark Adjustment (EBA), the Commonwealth sought to appropriate some of the savings for other budgetary areas (Burke, 1996). This practice was modified in 2001 when the government announced its intention to direct funds that were collected under the EBA back into specific education initiatives in the public school system (Kemp, 2001). As a result, the cost effective diversion of students to the private sector can, as far as higher per student spending permits, enhance the quality of the services on offer in the public sector.

However, per student funding is a very crude measure of student funding. For example, to the extent to which higher available funds are directed towards uses not valued by the parents of potential students, higher funding may do little to enhance perceived educational quality. Moreover, the change in the nature of the 
socio-economic mix of students remaining in the public system after the subsidy program may be viewed by some parents as an effective decline in the quality of the wider educational environment in the public school system. (For evidence on peer effects, see, for example, Zimmer and Toma, 2000; and Gaviria and Raphael, 2001.)

The enrolment decisions of the parents of school children are not only determined by the relative level of fees - the perception of the quality of the educational experiences offered to students in the two sectors is also likely to have a strong influence on decisions. As students switch into the private system, the marginal (in terms of willingness to switch) public education student will consider the improved public education quality as well as lower private school fees when deciding which system to attend. The extent to which an improvement in the perceived quality of the government sector induces higher enrolments in the government sector, away from the private sector, is referred to as the quality elasticity of demand for government education.

The higher this quality elasticity is, the less effective the subsidy program will be. In effect, the program has two competing and counterbalancing demand drivers. The subsidy program is based on a high price elasticity of demand for private schooling shifting substantial numbers into the private sector. This shift is offset to the extent that the private education subsidy increases per-student funding for public schools, and the extent to which this is perceived as enhancing educational quality there. Therefore there are three key questions on the demand side of the problem:

- What is the price elasticity of demand for private education?

- What will the resultant improvement in the public sector be?

- What is the quality elasticity of demand for the government sector?

Any serious education policy proposing increased private education subsidies in an attempt to improve both public and private education expenditures and outcomes needs to be based on judgments about the magnitudes of these elasticities. However, an issue often ignored when discussing education finance policy is the supply response of providers of private education to changes in subsidies and demand for their educational services.

The existing subsidy program, with its emphasis on parental choice, relies on the price elasticity of supply of private school places being relatively high - there is an implicit assumption that the private school system will take up substantial numbers without marked increases in cost structures and therefore fees. A low price elasticity of supply for private education would imply private school fee increases of a similar magnitude to the change in the subsidy, resulting in no changes in enrolments and large government transfers to private schools. These transfers may be captured by teachers in the form of higher wages or lower student staff ratios, or may be used for capital improvements by private schools, thereby enhancing their competitive edge over public schools. The activity of capitalising increases in government funding by non-government schools is confirmed 
empirically in Williams (1984). The problem in such cases is that subsidies may not reduce fees, choice may not be enhanced in a meaningful way, and the only beneficiaries may be the students and families originally using non-government schools. However, it is also possible that increased government funding to government schools may not improve educational outcomes.

There has been no research published in Australia integrating these three relationships to empirically evaluate the subsidy issue. Williams (1984 and 1985) considers the issue of public funding of non-government schools in Australia and provides demand elasticity estimates (based on aggregate data and relationships) while assuming the supply side is perfectly elastic. In the US, Martinello and West (1988 and 1991) and Frey (1991) addresses the simpler, but related question of whether government subsidies of private education, in the form of a tax credit, could reduce the public education budget without making any students worse off in terms of spending. That is, they study a subsidy scheme aimed purely at reducing the overall government contribution to education with all net savings from shifting students out of the public sector into the private system being returned to consolidated revenue, in order to reduce taxes, rather than being used to enhance the public education system. This body of work emphasises how the conclusions that can be drawn on the net impact of subsidy programs are highly sensitive to relative values of the price elasticities of supply and demand for private education.

The implications can be interpreted in two ways. The first is that the expected net saving for any given subsidy will vary depending on the set of elasticities ruling at the time. The second is that for any given set of elasticities, the magnitude of the net saving will depend on the size of the subsidy. The optimal size of the subsidy (optimal in terms of maximising the net savings to the government) is positively related to the size of the elasticities of demand and supply. That is, when parents are highly responsive to reductions in fees and the private school system is willing and able to absorb large numbers of students without major increases in their fee structures, government savings will be maximised by subsidies that are set at relatively high levels. With very low elasticities the optimal initiative from a government aiming to save funds would be to tax students attending private schools or at least offer a zero subsidy. This is because with low elasticities any subsidy does little in terms of inducing students to leave the public sector for private schools and any that do, tend to drive up school fees in the private sector substantially. The results of Frey's (1991) sensitivity analysis are summarised in Table 2 below. 


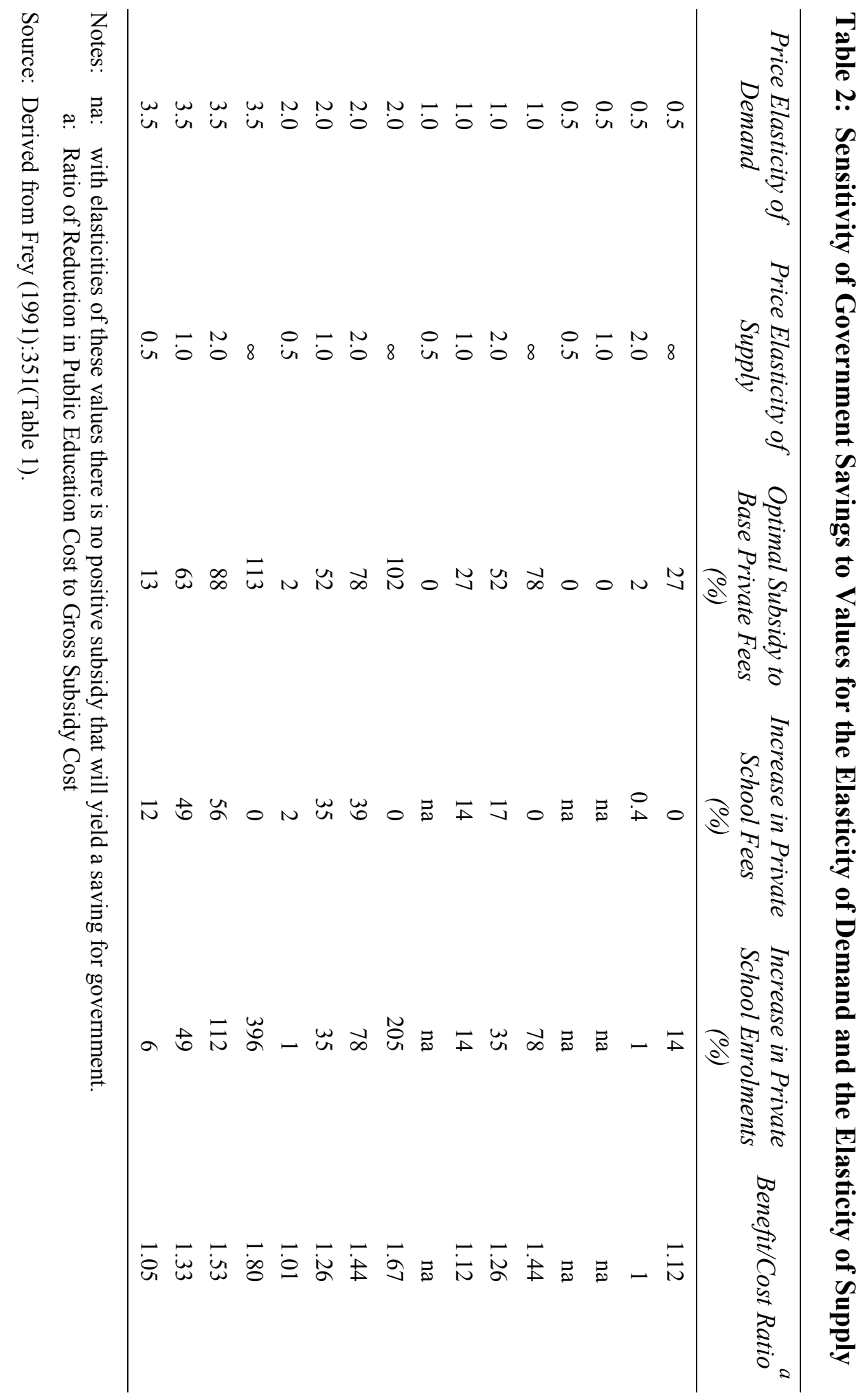


The elasticity values represent the percentage change in quantity demanded or supplied relative to a given percentage change in fees. For example, price elasticities of demand for private schooling of 0.5 or 1.5 indicate that demand for student places in the private sector would rise by five per cent or 15 per cent respectively in response to a 10 per cent reduction in private school fees. Similarly, a price elasticity of supply of two is consistent with a 20 per cent increase in the number of places offered in the private sector in response to a 10 per cent increase in private fees. Under general conditions in a competitive market this is also equivalent to saying that a 20 per cent increase in enrolments would result in a 10 per cent increase in costs and charges.

The symbol $\infty$ in the price elasticity of supply column indicates that under this scenario the supply of education places in the private sector is assumed to be infinitely responsive to fees charged. This means that the private sector is able to absorb all new students without an increase in student fees. Under this condition governments can always save if they select the right subsidy level. With an infinitely responsive supply side the optimal subsidy ranges from 27 per cent (with a price elasticity of demand of 0.5 ) up to 113 per cent (with a price elasticity of demand of 3.5). The corresponding benefit cost ratios (shown in the last column) range from 1.12 up to 1.80 .

Where the subsequent growth of the private sector would increase private school fees (a price elasticity of supply of less than infinity) the optimal subsidy is lower, as is the benefit cost ratio. For example, with a price elasticity of demand of 1 , a variation in the supply elasticity from infinity down to two would reduce the optimal subsidy from 78 per cent to 52 per cent and reduce the benefit cost ratio from 1.44 to 1.26 .

In terms of the Australian debate, the savings measured by Frey (1991) offer us some measure of the funds that may be redirected to the remaining public education students, offering potential improvements in public education. However, most of these studies have not considered how the effect of spending these budgetary savings on enhancing the now smaller public sector - the quality elasticity of public education - would change the analysis. Williams (1984 and 1985) acknowledges the response of private school enrolments to improvements in public schools and estimates, using Australian data, the elasticity of private school enrolments to public education expenditure to be -0.045 . Assuming that increased spending in schools increases quality dollar for dollar, Williams' result implies a 10 per cent increase in public education expenditure (and thus quality) would lead to a reduction of 0.45 per cent in private school enrolments. Thus the improved public education system will reduce migration to the private system, albeit a very small response, thereby reducing the potential improvements in the public system. ${ }^{1}$ This is why the savings suggested by Frey (1991) should be viewed as

1 Our assumption of a one-for-one relationship between education spending and quality simplifies the analysis. It is possible that education quality would rise by less than the change in expenditures, leading to larger predictions of quality elasticity. For example, if education quality rose by only 1 per cent when education expenditure rose by 10 per cent, we could infer from Williams' numbers that quality elasticity is -0.45 . 
an upper bound for the potential benefits to the public education system of private education subsidies.

Frey's (1991) results offer some support to the existing subsidy regime in Australia at the aggregate level. Average subsidies of just over $\$ 4,000$ per student (in the year 2000) could be expected to represent a subsidy on private school fees in the order of 30 per cent to 60 per cent (for private school fees of $\$ 14,000$ and $\$ 7,000$ respectively). Subsidies in this range are consistent with market conditions characterized by values of 1 or greater for both the price elasticity of demand and the price elasticity of supply. This means that the current subsidies could be expected to be effective in reducing aggregate budgetary outlays on education provided that:

- a 10 per cent reduction in private fees resulted in at least a 10 per cent expansion in the demand for private schooling; and

- a 10 per cent increase in enrolments in private schools caused private school fees to increase by no more than 10 per cent.

While one could speculate that elasticity values of at least 1 seem plausible for the Australian system on average, it is important to recall that the SES funding scheme provides markedly different subsidies to different private schools. For example, schools with an SES of at least 130 receive a grant equivalent to 13.7 per cent of AGSRC. If these high SES schools are high fee schools with fees of the order of $\$ 14,000$, this payment could represent 6 per cent or 7 per cent subsidy on actual school fees. On the other hand schools with an SES of no more than 85 could receive a subsidy of around 70 per cent of actual fees if they were relatively low fee schools with charges approximating the AGSRC.

Imposing an inverse relationship between the magnitude of the subsidy and the level of a school's SES would only be consistent with maximizing the financial effectiveness of the program if the values of the price elasticities of supply and demand were also both inversely related to the value of the SES. That is, the current funding formula would only optimise the education funding 'surplus' if low SES schools had higher elasticities of demand and supply than high SES schools. It is not clear that this relationship would hold in Australia.

While it seems the relatively rapid growth in the number of low SES schools in recent years is consistent with low SES schools having, on average, a higher price elasticity of supply than their high SES counterparts, the same may not apply to the price elasticity of demand. It is not unreasonable to assume that relatively exclusive private schools are likely to have high elasticities of demand (a substantial number of parents would be willing to move children into these schools if fees were lower) and low elasticities of supply (schools are unwilling to increase enrolments and thereby reduce exclusivity in return for higher fees or schools are at physical capacity, as waiting lists employed by many schools may suggest). From Table 2 it would appear that this scenario of high elasticities of demand (say 2 to 3.5 ) coupled with low elasticities of supply (say 0.5 ) would be consistent with small optimal subsidies of two per cent to 13 per cent. The current 
subsidies for many wealthy schools probably lie in this range. However, the benefit cost ratios associated with these optimal subsidies are very low, between 1.01 and 1.05. This implies that the existing range of subsidies to wealthy schools could well be optimal and in fact have a benefit that exceeds their cost but in an environment of limited public funds, these subsidies may not rank sufficiently high in terms of benefit cost ratios to guarantee funding on purely economic and financial grounds. However, it should be remembered that many government policies are not solely driven by economic benefits. These subsidies to wealthy schools may get over the line, in terms of funding, on political grounds or some other non-economic government objective.

Complicating the issue further is the fact that private schools are quite diverse, as are their student bodies, giving rise to a wide range of elasticities even for schools with similar SES scores. For example, some religious schools may differ markedly from other schools with a similar SES. They may have a high supply elasticity where they are very willing to take on new students in order to achieve secondary goals such as the promotion of a particular religion, while demand may be very inelastic because religious education is important to parents who send their children to such schools, implying there are few parents who would decide to send their children to such schools if price was to fall. These claims are relatively consistent with the analysis of non-government schools in Anderson (1992). In terms of the sensitivity analysis in Table 2, this case could imply optimal subsidies in the range of 27 per cent to 78 per cent (assuming the price elasticity of supply is infinity and the price elasticity of demand lies in the range of 0.5 to one). Once again, these subsidy levels are probably broadly consistent with the level of subsidies offered to many poorer religious based schools. Importantly, the benefit cost ratios of 1.12 to 1.44 associated with these subsidies would appear to justify these subsidies on financial grounds.

On the issue of the quality elasticity of public education demand, one could speculate that this would be relatively low if the alternative was an exclusive private school. That is, improvements in public schools would not easily entice private school students back into the public system - the exclusivity may be very important to these parents. These claims are focused purely on the higher and more exclusive end of the private school market and are speculative. Further empirical investigation is required.

The elasticity estimates in Williams (1984 and 1985) apply to pre-1980 data and are based on aggregate data. The diverse nature of the non-government school sector in Australia implies aggregate estimation of education demand relationships will struggle to reflect the true nature of the demand relationships for the various types of non-government schools. Given the great change in public and private schools since the early 1980's (with respect to enrolments and funding), a critical direction for future research on education financing in Australia is the development of estimates of demand and supply elasticities based on recent micro-level data, as in Rubinfeld and Shapiro (1989). Estimates of the quality elasticity of the demand for public education would also be helpful. Taken 
together, such data would be useful in determining equilibrium responses to policy changes in public and private education systems.

\section{Program Design Problems}

Several features of the SES funding program potentially impinge on its effectiveness as a means of improving the resources of public schools. These include poor targeting of potentially mobile enrolments and the differential rates for identical students at different schools, which is related to the reliance on average school rankings.

An inevitable problem with any program aimed at enhancing choice and mobility is the inability and or unwillingness of policy makers to target the specific people who make decisions on switching their children's enrolments between sectors. This applies to both the ERI and SES systems. Not all parents are willing to consider changing educational sectors. Importantly, there is a large number of parents committed to the private education sector who have the incomes to sustain their educational choice. These educational decisions are not influenced by the subsidy, so any government funding directed at such students under the program is potential wastage in terms of providing choice or facilitating the switching of such students into private schools. It would be difficult if not impossible to ascertain who the marginal public education families are, (those that would switch from public to private schools for a relatively small subsidy), in order to target subsidies exclusively to this group. To the extent that ability to pay is the key demand factor, means testing is likely to be the most practical method of identifying these marginal families and students. If non-government schools continued to charge a uniform fee to all students despite means tested subsidies, a change in the method of delivering subsidies would be required. It is likely that subsidy would have to be paid to the parent and would be offset against the fee charged by the non-government school, thereby enhancing mobility and choice for the marginal students.

The means testing characteristics of the program implied by the use of SES go some way to dealing with the issue of targeting. However, reliance on average school SES scores rather than individual family characteristics is a shortcoming of the program. For example, all students who attend schools with high SES scores are funded at relatively low rates. This means that while parents' choices are enhanced by the subsidy scheme, high SES schools are likely to be out of reach for students and families with low SES. Assuming a willingness and capacity to expand supply on the part of existing high SES schools, a truly means tested scheme would enhance choice further and allow greater numbers of low SES students to enrol in high SES schools. For example, Bearse, Glomm and Ravikumar (2000) show that means testing for education subsidies (vouchers) can increase total education expenditures and reduce inequality in the allocation of education expenditures. There is scope however for schools to recognize that enrolling students with low SES will lower the school's average SES and increase the subsidy paid for every student. In order for a high SES school to increase its 
government funding, it may be beneficial to offer scholarships to students with low SES. In this sense, the SES funding scheme may offer more mobility and choice than initially thought. It would be interesting and important to study average SES of each year level in a school, as it may be possible for schools to enrol low SES students in early years to attract extra funding and exclude them in the final year (assuming they are poor performers) in order to boost university entrance outcomes. This would not truly reflect an enhancement of choice and may suggest opportunistic behaviour on the part non-government schools; see Anderson (1992) for a discussion of such policies.

Differential funding between schools under both the SES and ERI systems generates stronger incentives for parents of students in government schools to shift their children to low SES (and high subsidy) schools rather than high SES (and low subsidy) schools. If the major factor constraining parents to public schools is a low ability to pay for private schooling, the outcome of this incentive structure could be to reinforce the segmentation of schools on the basis of SES, with relatively low SES parents in the public sector shifting their children to relatively low SES schools in the private sector. There appear to be no economic grounds for the government to bias subsidies and enrolments in this way. It could be argued that this is likely to have serious social implications, stratifying students by SES, operating to strengthen the exclusivity of high SES schools, to embed a class structure and potentially to reduce social and earnings mobility. To the extent to which high SES schools are also high ERI schools the impact of the two programs, in this regard at least, seem equivalent.

\section{Policy Implications}

The use of subsidies of private sector activities is both widely practiced and highly controversial. These programs can be cost effective in terms of saving public funds or providing greater resources for public sector activities. Their success in terms of budgetary effectiveness depends on the nature of the market environment in which they operate and the specific policy parameters.

A number of problems with the existing policy have been identified. An important issue is the lack of a strong link between the provision of subsidies and the potential willingness of students to shift between sectors. This poor targeting implies that part of private education subsidies are going to private school users that would never switch to the public system, implying unnecessary subsidies and, if the objective of subsidies is to enhance choice or improve the government school system, a wastage of public funds.

Simple solutions to the targeting issue are not apparent, as the identification of potentially mobile groups of students is problematic. If one accepts that lower income families have a greater unmet demand for private education than higher income families, the payment of subsidies to individuals on the basis of meanstesting of student's families (essentially a means tested voucher system) rather than assessing the average SES of schools may be one way to improve the targeting of subsidies. 
An important point to remember about the SES system of government funding to non-government education outside the Catholic system is that this subsidy scheme resembles a voucher scheme, because funding is provided on a per student basis and if a student switches from one private school to another, the old school loses the subsidy that the switching student entitled them to and the new school gains a subsidy for enrolling the student. This is a voucher in character if not in name.

The interpretation of the SES scheme as a means tested voucher is not as clear-cut. Means testing is typically understood as granting aid based on need, with people on low incomes receiving more aid than those on higher incomes. In the SES funding scheme, the school's average SES measures the means of an individual. A student with low SES (low income and occupation score) will receive a higher subsidy in as much as they may lower the average SES of the school they attend, thereby entitling themselves (along with the whole student body) to a higher per student subsidy or voucher. Clearly this is not what we expect from means testing. It makes it very hard for a family with low SES to have their child attend an expensive private school because the family's voucher will be the same as the voucher given to a family with the highest SES sending their child to the same school. This does not appear consistent with the governments stated objective of increasing choices available to parents although schools have the discretion to reduce fees for low SES students, for example by offering scholarships.

We conclude by noting that if market based approaches, which include subsidies, are to be successfully implemented, it is important that policymakers have a clear understanding of the demand and supply relationships for both private and public education. This requires improved estimates of demand and supply elasticities for private education. This would be a fruitful direction for further empirical research and would only improve education funding policies. The coexistence of the SES and ERI funding schemes arising from the Catholic school system opting out of the SES scheme will provide the opportunity to analyse parental responses to the different subsidy schemes and may assist in the estimation of the elasticities of interest.

Given our assumptions about policy objectives, the SES framework clearly exhibits shortcomings. Common with the ERI, the poor targeting of existing subsidies, through the use of average school rankings rather than individual means tests, makes for relatively ineffective policy. While the existing subsidy rates to private schools are of the broad order of magnitude that would be expected given the responsiveness of parents, on average, to changes in fees and the impact of higher enrolments of fees, the likely benefit cost ratios from subsidizing schools with high SES scores implies that the relatively small subsidies that are given to these schools are difficult to justify on financial grounds.

Some may argue that the various shortcomings of the SES funding scheme create a case against public funding of non-government schools. It should be emphasized that the scrapping of government funding for private schools could have serious financial implications for the whole of society. Not only will 
families with students in non-government schools be adversely affected, public school students may suffer from over crowding and taxes would have to be higher in order to fund the greater public expenditures.

Alternatively, an individually means tested voucher system would improve targeting and enhance parental choice, providing more opportunities for students with low SES to attend non-government schools with high SES and fees.

\section{References}

Anderson, D. (1992), 'The Interaction of Public and Private School Systems', Australian Journal of Education 36(3):213-36.

Bearse, P., G. Glomm and B. Ravikumar (2000), 'On the Political Economy of MeansTested Education Vouchers', European Economic Review 44(4-6):904-915.

Burke, G. (1996), ‘School Resources’, Australian Economic Review 116:401-8.

Commonwealth of Australia (2001), Gazette, No. 1, 19 November.

Commonwealth Schools Commission and Australian Bureau of Statistics (1979), Australian Students and Their Schools, Canberra.

Department of Education, Training and Youth Affairs (2000), 'Commonwealth Programs for Schools: Quadrennial Administrative Guidelines 2001 to 2004', Canberra.

Department of Employment, Education, Training and Youth Affairs (1997), 'Schools Funding: Consultation Report', Commonwealth of Australia, Canberra.

Department of Employment, Education, Training and Youth Affairs (1998), 'Schools Funding: SES Simulation Project Report', Commonwealth of Australia, Canberra.

Donnelly, K. (2001), 'Education Agenda: Beaujolais Bolshies', Institute of Public Affairs Review, 53(1):28.

Frey, D. (1991), 'Optimal-Sized Tuition Tax Credits Reconsidered: Comment', Public Finance Quarterly 19(3):347-354.

Gaviria, A. and S. Raphael (2001), 'School-Based Peer Effects and Juvenile Behaviour', The Review of Economics and Statistics 83(2):257-268.

Kemp, D. (2001), 'Federal Budget delivers for Government Schools', Media Release, Department of Education, Training and Youth Affairs, 22 May.

Martinello, F. and E. West (1988), 'The Optimal Size of the Tuition Tax Credit', Public Finance Quarterly 16(4):355-368.

Martinello, F. and G. West (1991), 'Education Budget Reductions Via Tax Credits: Some Further Considerations', Public Finance Quarterly 19(3):355-368.

Maslen, G. (2000), “"Give to rich" plan sparks outrage', The Times Educational Supplement, November 24:14. 
Ministerial Council on Education, Employment, Training and Youth Affairs (2003), 'National Report on Schooling in Australia 2000', http://www.curriculum.edu.au/anr/index.html

Rubinfeld, D. and P. Shapiro (1989), 'Micro-Estimation of the Demand for Schooling: Evidence from Michigan and Massachusetts', Regional Science and Urban Economics 19(3):381-98.

Steering Committee for the Review of Commonwealth/State Service Provision (2002), Report on Government Services 2002, AusInfo, Canberra.

Sydney Morning Herald (2002), 'Spelling out the education split', 27 May 2002.

Williams, R. (1984), 'Interactions Between Government and Private Outlays: Education in Australia, 1949-50 to 1981-82', Economic Record 60(171):317-25.

Williams, R. (1985), 'The Economic Determinants of Private Schooling in Australia', Economic Record 61(174):622-28.

Zimmer, R. and E. Toma (2000), 'Peer Effects in Private and Public Schools across Countries', Journal of Policy Analysis and Management 19(1):75-92.

The authors would like to thank two anonymous referees and Graeme Wells for helpful comments. 